(2)

\title{
REGIONAL ASPECTS OF THE DEVELOPMENT OF LARGEST ENTERPRISES IN THE CZECH REPUBLIC
}

\author{
Jan SUCHÁČEK ${ }^{\mathrm{a}}$, Petr SEĎA ${ }^{\mathrm{b}}$, Václav FRIEDRICH ${ }^{\mathrm{b}}$, Jaroslav KOUTSKÝc \\ ${ }^{a}$ Department of Regional and Environmental Economics, Faculty of Economics, \\ Technical University of Ostrava, Sokolská trída 33, 702 00, Ostrava, Czech Republic \\ ${ }^{b}$ Department of Mathematical Methods in Economics, Faculty of Economics, \\ Technical University of Ostrava, Sokolská trída 33, 702 00, Ostrava, Czech Republic \\ ${ }^{c}$ Department of Regional Development and Public administration,
}

Faculty of Social and Economic Studies, Jan Evangelista Purkyně University in Ústí nad Labem, Moskevská 54, 400 96, Ústí nad Labem, Czech Republic

Received 20 February 2017; accepted 08 April 2017

\begin{abstract}
Location processes are constitutive for the formation of economic landscape. Largest enterprises represent one of the most important units of territorial economies. Their role is palpable mainly in the sphere of employment, technological level, value chains, competition as well as overall economic power. It is far from surprising that the weight of enterprise headquarters is higher than that of their affiliates. Therefore, the main objective of our article is to analyze and assess the development of spatial organization of one hundred largest enterprise head offices in the Czech Republic from both quantitative and qualitative perspectives. Due to data limitations, size of the enterprise is measured by its turnover. Spatial distribution of one hundred largest Czech enterprises and its development over time represent the focal point of our evaluation from quantitative point of view. The analysis was based upon annually published top 100 databases. Qualitative assessment is underpinned by the results of the questionnaire, which was focused on particular location factors accentuated by largest enterprises. Consistency analysis and exploratory factor analysis provide us with useful instrument for the evaluation of qualitative dimension of the issue and help us to conceptualize location preferences of largest enterprises in the country.
\end{abstract}

Keywords: largest enterprises, quantitative perspective, qualitative perspective, regions, Czech Republic, factor analysis.

JEL Classification: D22, L10, L22, R10, R11, R30.

Corresponding author Jan Sucháček

E-mail: jan.suchacek@vsb.cz 


\section{Introduction}

Location decision-making considerably co-shapes not only contemporary but also future economic and social landscape. In essence, we concentrate on two basic perspectives: first, there is a specific demand side represented by enterprises and investors. These actors demand certain attributes and qualities of localities and regions. Second, location conditions of individual territories form a specific supply side. Final collocation of enterprises naturally reflects a large bulk of interplays between above mentioned supply and demand sides. In contrast to general economic categories, supply and demand we deal with bear a distinct spatial dimension (Aksoy, Marshall 1992; Markusen 1985; van Dijk, Pellenbarg 1999; Shephard, Barnes 2003; Johnston et al. 1994; Yserte et al 2016; Ascani et al. 2016; Suchacek 2015 or Vanhove, Klaasen 1987).

Large enterprises create rather relevant components of virtually all economic systems. Territorial organisation, differentiation as well as other qualities of individual economies are co-determined among others just by large firms' strategies, collocation and behavioural patterns. Put succinctly, large enterprises do matter in connection with both economic and geographical worlds.

When dealing with complex and abundant relations among territorial economies and large enterprises, organisational structures of firms are of utmost importance. Naturally, headquarters represent decisive nods for functioning of whole enterprises with numerous spatial implications on the one hand and affiliates form relevant but typically "pulled" components of enterprises on the other. Geographies of enterprises matter enormously.

In contrast to small or middle-sized firms, big enterprises possess undoubted economicpolitical power, which signifies their importance. This holds true for relatively little posttransition economy, of which the Czech Republic is a typical representative, even more. Spatial distribution of enterprise head offices co-determines societal-economic importance of localities and regions. It is also a driving factor, sui generis, of the materialisation of future socio-economic maps.

It should be stated that main economic activity does not necessarily take place in the spots where enterprise head offices are located and there are versatile forms of the geography of enterprise (Maier, Tödtling 1997). Still, headquarters of large companies are decisive in terms of the decisions about utilisation of enterprise profits, designing investment programmes or closure of affiliates (Fothergill, Guy 1990).

Development of spatial distribution of largest enterprises constitutes rather rare topic in the Czech Republic so far. In the eminent world economic and geographical literature, relations among large enterprises and territorial economies of various scales are the subject of close scrutiny (Dunning, Lundan 2008 or Bevan et al. 2004).

In relation to the economies at the national level, large enterprises influence mainly the balance of payments, employment, technological level and level of competition. In relation to regional or local economies, they affect mainly regional and/or local employment and can create important relations with suppliers at their territorial level, which further raises the employment. They also act as generators of innovation, higher productivity and better skills. 
Spatial divisions of labour (Massey 1984, 1995) accentuate relations among spatial organisation of the economy and the labour market. These relations are evaluated in the framework of wider societal structures. According to this conception, space is relative rather than absolute category and is of deeply hierarchical nature. It is necessary to distinguish contingent and necessary processes of socioeconomic character with territorial connotations. While necessary processes have much to do with the attributes of the economy itself, their contingent counterparts are strongly dependent on geographically strongly differentiated institutional characteristics of each single territory.

Thus, spatial divisions of labour are affected by socioeconomic character and evolution of individual territories (Frobel et al. 1980). These tendencies result in a certain duality of space, when executive managerial and/or research and development functions concentrate mostly into metropolitan areas, while their peripheral counterparts are dependent mostly on production. Enterprise hierarchy thus often correlates with settlement system (Maier, Tödtling 1997).

Even more interestingly, several researches (Massey 1984, 1995; Fothergill, Guy 1990) have found the closure of enterprise affiliates is based on the position within enterprise hierarchy rather than on efficacy of these organisational units. And manufacturing functions turned out to be the most vulnerable ones in terms of the closure. Not surprisingly, Massey (1984, 1995) suggests that geography of enterprise should strive for minimisation of distances and managerial functions should not be isolated from individual branches of firms.

Enterprise headquarters very often disregard entirely specific local and/or regional conditions. "External control" became a common practice in nowadays world and destinies of many places and regions are frequently shaped by pivotal actors residing elsewhere (Suchacek 2008).

Very often, branches of large companies represent so-called "Cathedrals in the Desert". These affiliates are named as "Cathedrals" as they utilise much more advanced technologies than other enterprises located in the peripheral region in question. And these cathedrals lie in the desert since they are fully subordinated to the head offices collocated typically in rather distant leading regions and are to a large degree isolated from the other firms in peripheral region. Thus, peripheral regions are substantially constrained when benefiting from the presence of these affiliates.

As a consequence of previously described trends, we are increasingly entitled to use the notion of mesoeconomics, which is represented mainly by large multinational corporations, which can utilise locational advantages at the worldwide scale. Mesoeconomics embodies the economic arrangements, which are based neither on the microeconomics, nor on the macroeconomic aggregate indicators. In other words, strict division of economics into macroeconomics and microeconomics is often a figment. Taking into consideration their economic-political influence, multinational corporations in a way formed a new category within economics (Holland 1976).

The main objective of this paper consists in analysis and assessment of the development of spatial distribution of one hundred largest enterprises in the Czech Republic. Size of the enterprise can be measured only through its turnover just for the sake of the lack of data. These enterprises will be contemplated at NUTS III territorial level. The issue will be evalu- 
ated not merely from quantitative but also from qualitative perspective. Via utilisation of this multiperspective approach we are able to draw on the causes and mechanisms forming the development of geographical structure of largest enterprises in the country.

The organisation of our article is as follows: after the introduction, materials and methodical approaches applied in this paper will be depicted thoroughly. The third chapter shows results of our research and its evaluation as well as interpretation. Quantitative part of our paper is based upon the evolution of large enterprises in the Czech Republic from spatial point of view. We were measuring these largest companies at the level of self-governing regions. Qualitative part of our research was devoted to next relevant aspects of the issue observed from the perspective of consistency analysis and exploratory factor analysis. After the application of factor analysis, the number of items embodying individual location factors shrank substantially. Newly formed factors express analysed location preferences of biggest firms in rather synthetic as well as meaningful manner. The last chapter of the paper is focused on research findings and conclusions.

The added value of the article consists in less frequented view on large companies in the Czech Republic. At the same time, an article can be perceived as a contribution to filling in several existing informational as well as methodical gaps. Last but not least, we tackle the issue of enormous importance, which is however stated only seldom in the Czech Republic.

\section{Materials and methods}

In order to find the concentration of economic power in particular country, standard world literature recommends to monitor the geographical distribution of five hundred largest enterprises within country's territory (see for instance Lyons 1994). Size of the enterprise is most frequently measured by its turnover. Taking into account unavailability of relevant data as well as the size of country's economy, our research will deal with the geographical distribution of one hundred largest enterprises in the Czech Republic. We will watch these largest - in terms of their turnover - enterprises at the level of self-governing or NUTS III regions.

Time series could be commenced from 1995 just for the sake of non-existence of data for previous years. Time series will help us to identify, which self-governing regions are friendly in terms of the location of largest enterprises.

From quantitative point of view, we will evaluate the development of spatial distribution of largest companies from absolute and relative perspectives. The absolute amount of enterprise head offices collocated in the given self-governing region is an important indicator, which provides us with basic view on enterprise economic power of the region in question. Relative weight of particular self-governing region in the framework of the Czech Republic will be assessed by means of the share of aggregate turnover of companies seating in the given region on the total turnover of one hundred largest Czech enterprises. Our research draws from annually published top 100 databases. Nonetheless, considering the scope of this article, we will discuss both absolute and relative indicators in the years 1995, 1998, 2001, 2004, 2007, 2010 and 2013. In that way, basic developmental tendencies in the field of the geography of biggest companies in the country can be captured. 
The qualitative part of our research was grounded in the survey accomplished by means of exploratory research in 2010. This survey focused primarily on factors and mechanisms influencing enterprise head office location decision-making. The data were gathered via electronic and telephone questioning.

Basic sample for the research contained altogether 190 enterprises. This amount was brought on by their iterative occurrence in top 100 databases as well as by bankruptcy of some of these biggest firms. Since 53 valid questionnaires returned to the researchers, rate of return amounted to approximately 28 percent.

At the beginning, telephone and e-mail contact to top or middle management was found out. The questionnaire was first sent to the e-mail of these people and in case of no response, the manager in question was contacted by means of telephone call. After the explanation and clarification of the research objective that manager obtained the questionnaire via e-mail again. This procedure finally turned out to be quite efficient. The research goes in a similar vein to Ivlev (Ivlev et al. 2015).

As indicated, the survey was executed through structured questionnaire. Likert scale covering the scale between -3 to +3 proved its usefulness for our purposes. The higher value at the scale, the higher intensity of the phenomenon in question. Thus, +3 marks full agreement, whereas -3 denotes full dissent and 0 stands for a neutral attitude.

In order to grasp the attributes of largest companies in the Czech Republic from both quantitative and qualitative perspectives, the following hypotheses will be tested:

H1. There is growing weight of Prague and Central Bohemia in both the amount of enterprises as well as percentage share on the aggregate turnover of 100 largest companies in the country.

H2. Location of large enterprise headquarters is most intensely affected by suppliercustomer relationships.

Our paper is underpinned by the methods of reliability analysis as well as exploratory factor analysis. Description and comparison are further methods amply utilized in our article.

\subsection{Consistency analysis}

When using factor analysis it is advisable to explore inner consistency of questions in the questionnaire at first. This consistency can be measured with a help of Cronbach's alpha test statistics. This statistic quantifies possible dependencies among individual items in the battery of questions that are quantified by same ordinal scale. Cronbach's alpha therefore illustrates the rate of inner consistency of items in the questionnaire (Cronbach 1960). Value of this statistic denotes the extent to which the values of each item in the battery in the questionnaire differ.

Cronbach's alpha statistics has to range from 0 to 1 . When Cronbach's alpha reaches small values (if $\alpha<0.5$ ) it can be interpreted as low consistency or high diversity of items. Contrary to that, higher value of Cronbach's alpha (if $\alpha>0.9$ ) denotes that there can be observed very strong inner dependency among individual questions in the questionnaire. Nevertheless, it doesn't confirm the hypothesis that all questions in the battery are evalu- 
ated in a similar way. It denotes that all respondents express similar preferences. Cronbach's alpha can be written as follows:

$$
\alpha=\frac{p}{p-1}\left(1-\frac{\sum_{i=1}^{p} \operatorname{var}_{i}}{\operatorname{var}}\right),
$$

where $\operatorname{var}_{i}$ denote variances of particular items of the battery of questions, while var represents variance of total score of the whole battery, and $p$ is the number of items in the battery.

Before we deal with exploratory factor analysis it is recommended that the value of Cronbach's alpha should be neither too low, nor too high. In optimal case, the mentioned statistics should range around the value of 0.7 . Hence, individual questions in the battery are mutually very well distinguishable. It should simultaneously hold that the variability of all questions is well comparable.

\subsection{Exploratory factor analysis}

The methods of factor analysis are usually applied in psychology, sociology, marketing and so on. However, utilization of this analysis in regional studies is quite rare. Factor analysis is a multivariate statistical method whose aim is to describe observed variability among original variables that are correlated in a simplified manner. For the purpose of this paper just exploratory factor analysis will be applied. The primary function of factor analysis is to reduce the number of variables to a certain smaller amount. That amount embodies unmeasurable variables standing in the background. In other words, factor analysis aims to identify common variations taking into account latent variables that cannot be observed directly (Meloun et al. 2012).

The procedure of factor analysis is based on a sample correlation and partial correlation coefficients. Hence, particular factors can be constituted by linear combinations of originally observed variables $Y_{1}, \ldots, Y_{p}$. The number of extracted factors should be lower than the number of original variables. Hence, the dependence between extracted factors and variables should be explained in a simple way. The idea of factor analysis is to name newly extracted factors since each factor may theoretically replace several original variables. In addition to this, factor analysis helps us to determine and clarify mutual relationships among observed variables.

The methods of factor analysis cannot be utilized on any data sample. We have to check, if the factor analysis is applicable or not. Kaiser-Meyer-Olkin (KMO) rate and Bartlett's test of sphericity serve as most commonly used indicators when verifying mentioned dependence (Mooi, Sarstedt 2011). Both statistical tools are based on the correlation matrix and matrix of partial correlation coefficients. KMO rate has always to reach the values between 0 and 1 . KMO rate is defined by the quotient of the sum of squares of the correlation coefficients to the sum of the squared correlation and partial correlation coefficients (Ramsay, Silverman 1997). To apply factor analysis, the KMO rate should reach at least 0.5 . Another 
way how to easily determine whether the variables are suitable for factor analysis is to test the null hypothesis that the correlation matrix of the variables is unitary. If we reject this null hypothesis, a factor analysis makes a sense. To test the null hypothesis it is usually used Bartlett's test of sphericity.

Mathematically, factor analysis procedure can be described as an expression of the investigated standardized variables $Y_{i}$ using a linear combination of a smaller number of hypothetical factors $F_{k}$ :

$$
Y_{i}=f_{i 1} F_{1}+f_{i 2} F_{2}+\ldots+f_{i k} F_{k}+u_{i}
$$

for $i=1,2, \ldots p$, where $p$ expresses number of variables, $k$ is number of extracted factors, $u_{i}$ denotes residual part of the variable $Y_{i}$. It is assumed that $u_{i}$ is not correlated with extracted factors. Constants $f_{i j}$ are called factor loadings. They can be interpreted as correlation coefficients between the observed variables and factors. The sum of the squared factor loadings represent a part of variability of the variable $Y_{i}$ that is explained by all the factors. This sum is called the communality of variable $Y_{i}$.

The results of exploratory factor analysis are inconclusive. This is due to the fact that there are numerous methods of extraction, rotation and calculation the score factors. Kaiser's rule is one of the options that compare the variance of factors with the variance of manifest variables. Factor analysis includes only those factors whose variance is greater than one. A factor that takes lower value is ignored. It is worth noting that the variance of individual factor can be mathematically determined as the Eigenvalue of covariance or correlation matrix. Scree plot represents a graphical method for determining the number of factors. This is actually declining plot of Eigenvalues of all factors that are arranged from the highest to the lowest. This approach will be applied also in this paper.

Methods of extraction of factors are in fact the methods how to determine the number of factors and related size of factor loadings. The principal components method, the maximum likelihood method, the least squares and the generalized least squares methods belong to the most commonly used methods of extraction (Rencher, Christensen 2012). Principal component indicates uncorrelated factors that are arranged by descending order according to their variance such that first factor has the greatest variance and the last factor the lowest one.

Regardless the method of factor extraction there is infinite number of solutions. It means that there exist endless other alternatives that describe the data equally well for every estimated loading factors. Therefore, in the second phase of factor analysis extracted factors have to be transformed so that we can interpret them as clearly as possible. Practice has shown that such factors whose factor loadings have the values close to either one or zero can be interpreted in the best way. This means that each manifest variable is strongly correlated with only some of the factors and other factors are correlated weakly only. This phase is called rotation of factors. There have been proposed many methods for rotation of factors. Most of them are based on a function of all elements of the matrix of factor loadings. Varimax, Quartimax, Equamax, Oblimin and Promax rotations are the most usually applied ones (Rencher, Christensen 2012). It is assumed that latent variables should be a kind of independent and therefore uncorrelated variables. The first step is to decide 
between orthogonal and oblique rotations. When using orthogonal type of rotation there are extracted uncorrelated factors.

Varimax type of rotation belongs to the group of orthogonal rotations. This technique minimizes the number of the variables that have high loadings with any common factor. We can consider it a method that simplifies extracted factors and makes easier to interpret them. The essence of this rotation is to maximize the variance of the squares of factor loadings in the columns. This method tends to create more than one common factor. Varimax rotation is as a rule applied to the scaled factor loadings. Varimax method attempts to find the maximum of quantity $V$ :

$$
V=\frac{1}{p} \sum_{j=1}^{k}\left[\sum_{i=1}^{p}\left(\tilde{f}_{i j}\right)^{4}-\frac{1}{p}\left(\sum_{i=1}^{p}\left(\tilde{f}_{i j}\right)^{2}\right)^{2}\right],
$$

where $\tilde{f}_{i j}$ are scaled factor loadings of the $i$-th variable on the $j$-th factor after rotation that can be expressed as $\tilde{f}_{i j}=\frac{f_{i j}}{c_{i}}$ where $c_{i}$ is the communality for variable $i$ (Hebák et al. 2005). The principle of Varimax rotation can be demonstrated in two-dimensional space by Figure 1. More precisely, both axes represent extracted factors that rotate the way that variables $Y_{i}$ create two clusters of points.

To summarize, in this paper we will utilize exploratory factor analysis based on principal components method and related Varimax type of rotation.

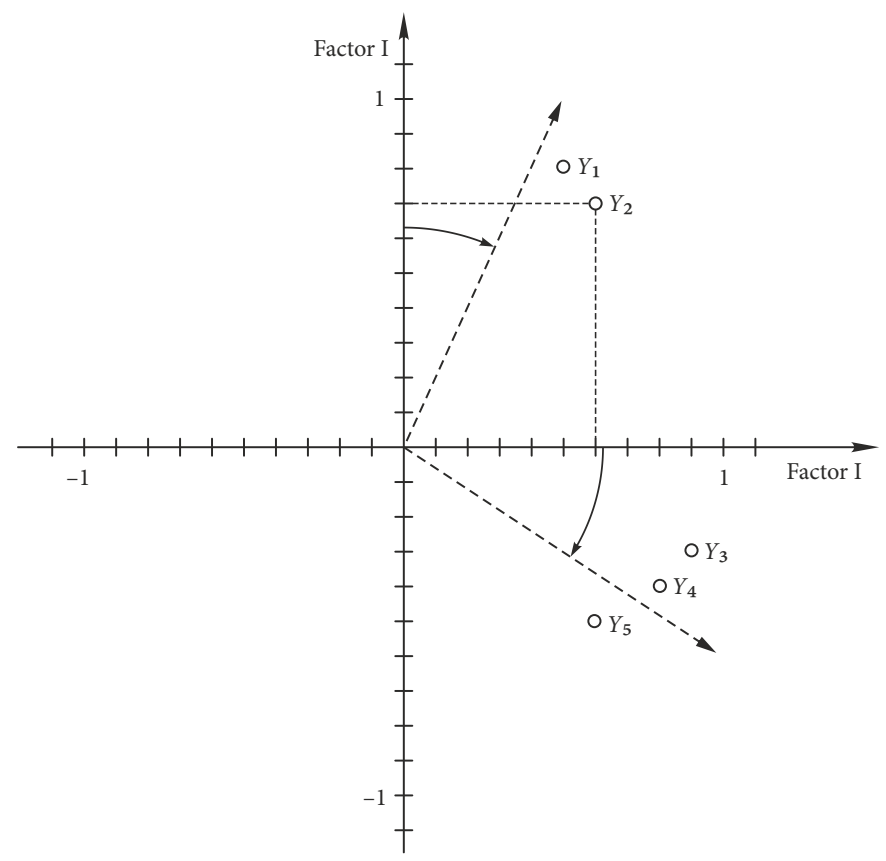

Fig. 1. Saturation of factors after Varimax rotation Note: Meloun et al. (2012), modified by authors. 


\section{Results and discussion formulas}

The following subchapters concentrate on quantitative and qualitative view on the development of spatial distribution of large enterprises in the Czech Republic.

\subsection{Regional dimension of the development of large enterprises in the Czech Republic from quantitative perspective}

Collocation of head offices of largest enterprises in the Czech Republic can be perceived as a certain manifestation and at the same time also a factor of regional differentiation of the country in transformation and post-transformation periods. Our analysis starts in 1995, when geographical organization of country's biggest firms was still considerably affected by path-dependency on previous developments, certain inertia of economic-territorial structures as well as not-yet-exposed results of the initial period of transformation.

As it can be derived from Tables 1 and 2, in 1995, the capital city proved to be the winner in both evaluated indicators. Prague's position was based on the presence of headquarters of large national enterprises or foreign trade companies rather than on the secondary economic sector previously accentuated by communist governments.

The dominance of the whole Central Bohemian space including Prague and Central Bohemia was palpable with even higher intensity, with the number of firms 45 and $56 \%$ of the share on the aggregate turnover of largest enterprises in the Czech Republic. In 1995, one could contemplate also quite good position of Moravian-Silesian and Usti regions. What do they have in common is a relative density of the population and prevalence of traditional industrial branches that however became rather vulnerable in a new economic conditions.

On the other hand, some regions of more rural character, such as Vysocina or Olomouc were able to attract just minimal number of headquarters. An interesting development could be observed in Zlin region with its dynamic growth of small and middle-sized firms, which however represent a completely different category than large enterprises. At the urban level, the most companies seated in large cities and towns, such as Prague, Brno, Ostrava, Plzen as well as Usti nad Labem. Naturally, taking into consideration unfinished privatization and running transformation processes, year 1995 can be treated merely as a beginning of development of large enterprises spatial pattern in the country and the point of departure for our research.

It is worth noticing that in both tables within this subchapter, Prague and Central Bohemia were aggregated into one region. Thus, one can monitor individual characteristics of both NUTS III regions as well as results of the united region composed of Prague and Central Bohemia. Aggregated region is already in consonance with natural geographical characteristics. This unification was accomplished also due to the lowering the influence of Prague, which represents a specific outlier within country's NUTS III territories. This approach proved its usefulness many times (see for instance Suchacek et al. 2014, 2015, 2016).

Large economic problems that emerged in 1997 and projected themselves primarily in 1997 and 1998 redrew the map of large enterprise headquarters in the Czech Republic. First, Prague and whole Central Bohemian space further strengthened their already exclusive positions. Capital city also fortified its position as the centre of tertiary sector in the country. 
Table 1. Regional differentiation of 100 largest companies

\begin{tabular}{lccccccc}
\hline \multirow{2}{*}{ Region } & \multicolumn{7}{c}{ Year } \\
\cline { 2 - 8 } & 1995 & 1998 & 2001 & 2004 & 2007 & 2010 & 2013 \\
\hline Central Bohemia + Prague & 45 & 54 & 57 & 59 & 56 & 53 & 48 \\
\hline Prague & 39 & 47 & 48 & 50 & 50 & 48 & 44 \\
\hline Central Bohemia & 6 & 7 & 9 & 9 & 6 & 5 & 4 \\
\hline South Bohemia & 4 & 3 & 2 & 3 & 3 & 1 & 4 \\
\hline Plzen & 4 & 4 & 4 & 4 & 4 & 4 & 4 \\
\hline Karlovy Vary & 2 & 1 & 1 & 1 & 1 & 2 & 1 \\
\hline Usti & 9 & 9 & 8 & 6 & 5 & 4 & 8 \\
\hline Liberec & 2 & 1 & 1 & 2 & 3 & 3 & 2 \\
\hline Hradec Kralove & 2 & 2 & 4 & 2 & 2 & 2 & 3 \\
\hline Pardubice & 4 & 1 & 2 & 2 & 3 & 3 & 4 \\
\hline Vysocina & 1 & 1 & 2 & 2 & 2 & 3 & 4 \\
\hline South Moravia & 7 & 6 & 6 & 4 & 4 & 6 & 6 \\
\hline Olomouc & 1 & 2 & 0 & 1 & 1 & 1 & 0 \\
\hline Zlin & 5 & 3 & 1 & 1 & 1 & 4 & 4 \\
\hline Moravia - Silesia & 14 & 13 & 12 & 13 & 15 & 14 & 12 \\
\hline
\end{tabular}

Note: Top 100 and authors' calculations.

Second, other important regions, such as South Moravia, Plzen region or MoravianSilesian region were mostly stagnating or even decreasing in terms of both the amount of representatives among country's top 100 enterprises as well as their ratios on the aggregate turnover of these top 100 firms. The amount of self-governing regions with mere one representative within top 100 firms increased too and concerned Karlovy Vary, Liberec, Pardubice and Vysocina regions. Regional differentiation as to top 100 enterprises had a rising tendency.

In 2001, the capital city as well as Central Bohemia further improved in both monitored indicators (for more information see Tables 1 and 2). They flourished as for the number of firms as well as in terms of region percentage share on the aggregate turnover of top 100 enterprises. The amount of large companies remained the same in South Moravia, Karlovy Vary, Liberec and Plzen regions, whereas other self-governing regions witnessed slight decrease or increase as to the amount of large firms. It is also worth noticing that Olomouc region was unable to attract any of 100 largest companies in the country. Naturally, smaller numbers of large companies in majority of regions stands behind augmentation of their volatility within contemplated hierarchy.

Between 2001 and 2004, South Bohemia and Usti regions worsened their score in both the number of enterprises as well as regional share on total turnover of 100 largest enterprises. On the contrary, Prague managed to improve its results again. In 2004, Prague altogether with Central Bohemia reached the record amount of representatives among 100 largest firms. And the same holds true for Moravian-Silesian region. After the break, Olomouc region returned on the map of largest enterprises with just one company. 
Table 2. Regional differentiation of 100 largest companies in terms of their percentage share on the aggregate turnover

\begin{tabular}{lccccccc}
\hline \multirow{2}{*}{ Region } & \multicolumn{7}{c}{ Year } \\
\cline { 2 - 8 } & 1995 & 1998 & 2001 & 2004 & 2007 & 2010 & 2013 \\
\hline Central Bohemia + Prague & 56.08 & 61.90 & 64.38 & 66.72 & 70.02 & 69.14 & 67.88 \\
\hline Prague & 46.99 & 46.23 & 45.72 & 54.28 & 57.59 & 56.75 & 55.26 \\
\hline Central Bohemia & 9.09 & 15.67 & 18.66 & 12.44 & 12.43 & 12.39 & 12.62 \\
\hline South Bohemia & 1.82 & 1.36 & 1.74 & 2.34 & 2.12 & 0.36 & 2.41 \\
\hline Plzen & 4.51 & 4.53 & 2.56 & 2.33 & 3.21 & 3.07 & 2.22 \\
\hline Karlovy Vary & 1.08 & 0.50 & 0.40 & 0.39 & 0.44 & 0.57 & 0.29 \\
\hline Usti & 8.23 & 7.83 & 8.11 & 3.52 & 2.03 & 1.69 & 2.69 \\
\hline Liberec & 0.75 & 0.35 & 0.58 & 1.06 & 1.37 & 1.03 & 0.78 \\
\hline Hradec Kralove & 1.69 & 1.46 & 2.56 & 1.01 & 0.70 & 0.62 & 0.90 \\
\hline Pardubice & 1.81 & 0.42 & 1.11 & 2.97 & 4.30 & 5.32 & 4.95 \\
\hline Vysocina & 0.35 & 0.33 & 0.98 & 1.09 & 1.22 & 1.17 & 1.53 \\
\hline South Moravia & 4.16 & 3.90 & 4.16 & 2.38 & 1.80 & 3.99 & 6.44 \\
\hline Olomouc & 0.38 & 0.79 & 0 & 0.37 & 0.39 & 0.36 & 0 \\
\hline Zlin & 2.60 & 1.86 & 1.00 & 0.40 & 0.33 & 1.04 & 1.13 \\
\hline Moravia - Silesia & 16.54 & 14.77 & 12.42 & 15.43 & 12.09 & 11.64 & 8.78 \\
\hline
\end{tabular}

Note: Top 100 and authors' calculations.

Central Bohemia, which forms a compact territory around the capital city, retained the amount of the firms, however deteriorated as for the share on aggregate turnover of all 100 top companies in the Czech Republic. It should be added that region's results were strongly influenced by large car manufacturer Skoda auto.

It might be stated that concurrently with the rough completion of fundamental privatization and transformation measures and steps, the noticeable process of ownership concentration emerged. Naturally, this process finds also its ample spatial manifestations.

Year 2007, which is also intercepted in Tables 1 and 2, represents a certain turning-point in the development of regional differentiation of 100 largest enterprises in the country. First, the amount of firms in Central Bohemian space did not grow any more. Nonetheless, percentage share on aggregate turnover of one hundred largest firms in the country reached its top value $70.02 \%$. Following years already witnessed its slight decrease. Ustí region again weakened its previous position. Somehow contradictory trends could be contemplated in Moravian-Silesian region, where the number of firms reached a record value 15 and concurrently, region's share on aggregate turnover of top companies declined.

Three years later, in 2010 we could contemplate how largest enterprises in individual self-governing regions coped with the consequences of financial and economic crisis. Central Bohemian space slightly worsened its position and the same applies also to MoravianSilesian and Usti regions. On the contrary, Zlin region proved to be quite resilient and improved its score considerably.

Last columns of Tables 1 and 2 present a fresh view on regional differentiation of 100 largest enterprises in the country. Improvement of South Moravia and mainly that of Usti 
region are salient. Next region, which remarkably improved its ranking - during the period of 6 years, however - is Vysocina. Olomouc region remains comparatively weak within researched categories.

During the period our research was conducted, basic spatial pattern of largest enterprises has been formed. Position of the capital city together with neighbouring Central Bohemia remains exclusive, the next position is occupied by Moravia-Silesia, which constitutes the region of traditional industry. Ranking of other self-governing regions is pretty volatile and arguably will not change in the short run. Last, but not least, it happened two times, when Olomouc region had zero companies among top 100 in the Czech Republic.

Previous paragraphs provided us with plastic view on the development of the geography of largest enterprises in the Czech Republic. In that way, quantitative dimension of our paper has been fulfilled. As already indicated, this will be complemented by a qualitative assessment of the location preferences of largest firms in the country, which is the subject of the following subchapter.

\subsection{Spatial distribution of large enterprises in the Czech Republic from qualitative perspective}

Qualitative perspective forms an appropriate complement to previously expressed quantitative spatial view on the development of headquarters of largest enterprises in the Czech Republic. Reliability analysis constitutes a useful point of departure for qualitative part of our analysis. Cronbach's alpha value is 0.869 , which signifies questioned managers evaluated location factors of large enterprises in a consistent manner and no assessed item was is discrepancy with other items.

The most intense consistence has been reached in case of location factors named "the proximity to suppliers" and "availability of raw materials". Contrary to that, the weakest consistence applied to factors labelled as "historical tradition" and "agglomeration economies”. Fundamental attributes of examined location factors can be seen in Table 3.

Table 3. Fundamental attributes of examined location factors

\begin{tabular}{|c|c|c|c|c|c|}
\hline \multicolumn{6}{|c|}{ Descriptive Statistics - Item Analysis } \\
\hline Item & Mean & SD & Item & Mean & $\mathrm{SD}$ \\
\hline Infrastructure & 2.32 & 0.644 & Closeness of similar firms & 1.19 & 1.020 \\
\hline Geographic location & 2.15 & 0.690 & Proximity to competitors & 1.17 & 1.051 \\
\hline Quality of entrepreneurial milieu & 1.77 & 0.577 & Proximity to decisive authorities & 1.13 & 1.093 \\
\hline Proximity to suppliers & 1.58 & 1.046 & Willingness of managers to move & 1.13 & 1.057 \\
\hline Availability/quantity of workforce & 1.57 & 0.821 & Land price & 1.02 & 0.909 \\
\hline Quality of local workforce & 1.56 & 0.998 & National policies & 0.92 & 1.036 \\
\hline Proximity to customers & 1.54 & 1.038 & Public administration system & 0.88 & 0.963 \\
\hline Agglomeration advantages & 1.49 & 0.973 & Quality of environment & 0.41 & 1.236 \\
\hline Availability of raw materials & 1.32 & 1.504 & Historical tradition & 0.40 & 1.166 \\
\hline Low wage requirements & 1.23 & 1.281 & Cultural facilities & -0.17 & 1.438 \\
\hline Image/prestige of the place & 1.19 & 0.786 & Sport facilities & -0.38 & 1.345 \\
\hline
\end{tabular}

Note: authors. 
While infrastructure and geographical location proved the most important as to the headquarters' location, the opposite holds true for sport and cultural amenities, historical tradition as well as the quality of environment. This fact is in seeming discordance with current popularity of soft location factors, which abound in numerous spatially-orientated analyses; in reality, the questioned managers of largest enterprises do take into account soft location factors but in their answers they accentuate predominantly factors directly involved in enterprise productivity. This can be perceived as sui generis a demonstration of their fidelity and loyalty to companies, where they are employed.

It is worth noticing that location factor called "proximity to decisive authorities" reached perceptibly higher mean than the next location factor named "public administration system". Since the latter deals mainly with the structure and the quality of the performance of public administration, these location factors are somehow of a different character.

As for variability of researched factors, the largest congruence has been reached in case of items, such as quality of entrepreneurial milieu, infrastructure and geographical location. Contrary to that, the largest differentiation of opinions concerned availability of raw materials and cultural and sport facilities.

Table 4. Kaiser-Meyer-Olkin measure of sampling adequacy and Bartlett's test

\begin{tabular}{lcc}
\hline \multicolumn{3}{c}{ KMO and Bartlett's Test Mean } \\
\hline Kaiser-Meyer-Olkin Measure of Sampling Adequacy & & 0.721 \\
\hline \multirow{3}{*}{ Bartlett's Test of Sphericity } & Approx. Chi-Square & 428.7 \\
\cline { 2 - 3 } & $\mathrm{df}$ & 136 \\
\cline { 2 - 3 } & Sig. & 0.000 \\
\hline
\end{tabular}

Note: authors.

The next step of the qualitative part of our analysis was devoted to the testing of the pertinence of factor analysis. As it can be observed in Table 4, Bartlett's test of sphericity shows it is possible to execute factor analysis. Kaiser-Meyer-Ohlin measure of sampling adequacy confirms that factor analysis makes a sense and identification of factors can be accomplished.

Communalities of researched location factors reach the values between 0.5 and 0.92 (see also Fig. 2). On average, variability of individual location factors is accounted for by factor analysis from $70 \%$.

Factor analysis best explains items named "proximity to suppliers" and "availability/ quantity of workforce". The opposite holds true for "national policies" and "price of the land" presented in Figure 2.

Figure 3 shows the scree plot for analysed items. Since the correlation matrix contains five respective numbers, the recommended amount of factors is five. These five factors explain $70.3 \%$ of variability of location factors. This is adequate to apply factor analysis just for the sake of the possibility to express location factors forming the spatial distribution of large enterprise headquarters in the country in rather synthetic manner. 


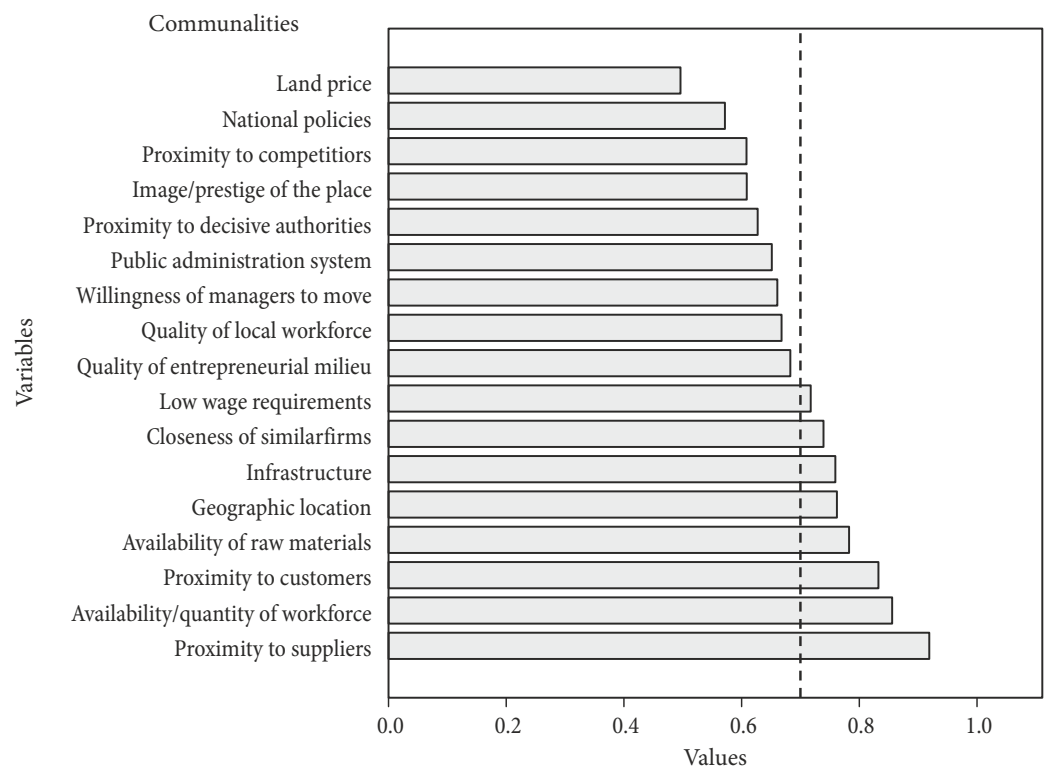

Fig. 2. Communalities of analysed location factors Note: authors.

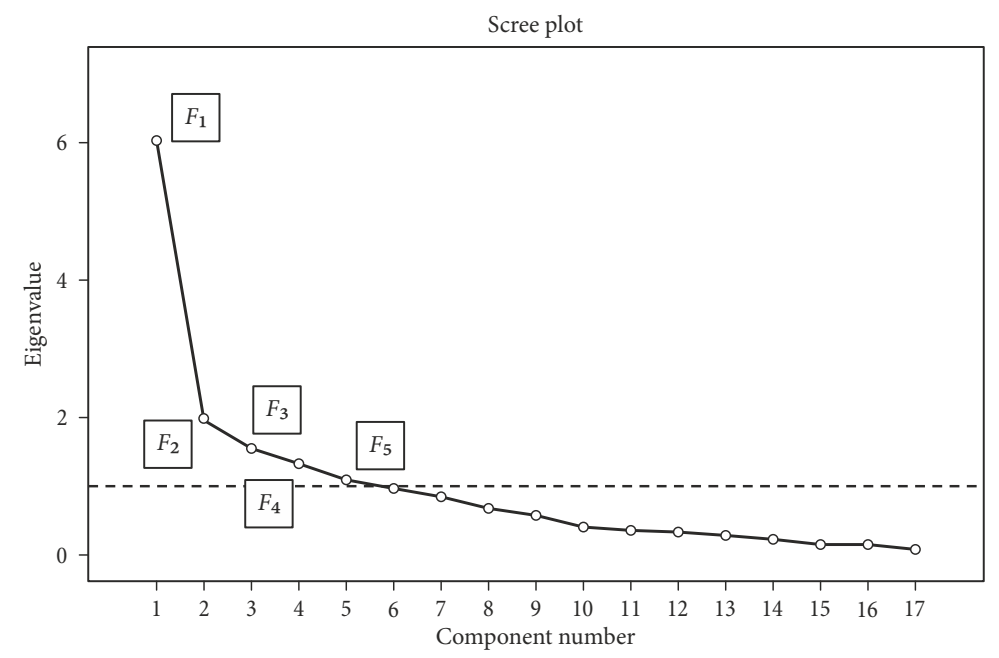

Fig. 3. Scree plot for location factors Note: authors.

Table 5 provides us with the information on the influence of Varimax rotation to location factors in question. While before Varimax rotation the distribution of variances among individual components was strongly uneven, after the application of that rotation the range of variances shrank sharply. 
Table 6 presents the results of accomplished factor analysis. As it can be seen, the table shows just main factor loadings that are higher than 0.5 . Selection and Varimax rotation led to the lowering of original number of 22 items to the final 17 variables. The amount of items, which are significantly bound to one factor, ranges between 2 and 4 .

Table 5. Initial values of items and values of items after Varimax rotation

\begin{tabular}{ccccccc}
\hline \multirow{7}{*}{ Component } & \multicolumn{5}{c}{ Total Variance Explained } \\
\cline { 2 - 7 } & Total & \% of Variance & Cumulative \% & Total & \% of Variance & Cumulative \% \\
\hline 1 & 6.040 & 35.532 & 35.532 & 2.823 & 16.608 & 16.608 \\
\hline 2 & 1.954 & 11.493 & 47.025 & 2.577 & 15.159 & 31.767 \\
\hline 3 & 1.537 & 9.041 & 56.067 & 2.397 & 14.098 & 45.865 \\
\hline 4 & 1.329 & 7.820 & 63.886 & 2.256 & 13.270 & 59.134 \\
\hline 5 & 1.091 & 6.418 & 70.305 & 1.899 & 11.170 & 70.305 \\
\hline
\end{tabular}

Extraction Method: Principal Component Analysis.

Note: authors.

Table 6. Results of factor analysis

\begin{tabular}{|c|c|c|c|c|c|}
\hline \multicolumn{6}{|c|}{ Rotated Component Matrix } \\
\hline & \multicolumn{5}{|c|}{ Component } \\
\hline & $\mathrm{F}_{1}$ & $\mathrm{~F}_{2}$ & $\mathrm{~F}_{3}$ & $\mathrm{~F}_{4}$ & $\mathrm{~F}_{5}$ \\
\hline Proximity to suppliers & 0.906 & & & & \\
\hline Proximity to customers & 0.881 & & & & \\
\hline Availability of raw materials & 0.731 & & & & \\
\hline Quality of entrepreneurial milieu & & 0.733 & & & \\
\hline Image/prestige of the place & & 0.723 & & & \\
\hline Closeness of similar firms & & 0.692 & & & \\
\hline Willingness of managers to move & & 0.554 & & & \\
\hline Land price & & & 0.691 & & \\
\hline Proximity to competitors & & & 0.679 & & \\
\hline Public administration system & & & 0.599 & & \\
\hline Proximity to decisive authorities & & & 0.535 & & \\
\hline Availability/quantity of workforce & & & & 0.830 & \\
\hline Low wage requirements & & & & 0.741 & \\
\hline Quality of local workforce & & & & 0.634 & \\
\hline National policies & & & & 0.565 & \\
\hline Geographic location & & & & & 0.809 \\
\hline Infrastructure & & & & & 0.788 \\
\hline
\end{tabular}

Note: authors. 
Interpretation of newly created five factors will be as follows:

- Factor 1 that can be labeled "supplier-customer relationships" contains the following location factors: proximity to suppliers, proximity to customers and availability of raw materials.

- Factor 2, which can be synthetically named "attributes of place" includes quality of entrepreneurial milieu, image/prestige of the place, closeness to similar firms and willingness of managers to move.

- Factor 3 can be succinctly called "other external influences" and comprises the following location factors: land price, proximity to competitors, public administration system and proximity to decisive authorities.

- Factor 4 that can called "labour market" encompasses availability/quantity of workforce, low wage requirements, quality of local workforce and national policies.

- Factor 5 can be briefly named "wider geographical position" and includes geographical location and infrastructure.

As it turned out, the accomplishment of factor analysis was meaningful and considerably facilitated our interpretations.

\section{Conclusions}

Debate over the issue of the regional dimension of the development of largest enterprises in the Czech Republic is relatively new. That is why our results bring a desirable contribution to that discussion. From quantitative point of view, we are entitled to talk about a distinct dominance of the whole Central Bohemian territory, with especially pronounced position of the capital city. The next place in the quantitative ranking belonged to traditionally industrial Moravian-Silesian region in fact during the whole analyzed time span. Positions of other self-governing regions turned out pretty volatile just for the sake of the small amount of their companies within Czech top 100. In certain years, Olomouc region was unable to lure any of 100 largest enterprise head offices in the country.

At first glance, position of the whole Central Bohemian space is still gradually improving, but last years witnessed the change in these tendencies. In terms of the number of enterprises, Prague and Central Bohemia reached the peak in 2004. As for percentage share on the aggregate turnover of 100 largest enterprises in the country, the same holds true for the year 2007. Thus, we were unable to confirm hypothesis $\mathrm{H} 1$ formulated at the beginning of the article. Seemingly surprising shrinking weight of the whole Central Bohemian space is in compliance with Czech Republic's settlement system on the one hand as well as objective processes including excessive costs in Prague or endeavours of regional self-governments on the other. Still, Prague and Central Bohemia remain a clear leader in terms of the geography of largest enterprises.

From qualitative perspective, our research brought ample evidence that traditional hard location factors, among which infrastructure or geographical location can be ranked, still play an important role during large enterprise headquarters' location decision-making. Factor analysis helped us to reduce initial amount of 22 location factors to 5 factors explaining $70.3 \%$ of the variance of location preferences. On the basis of factor analysis accomplished 
within our paper, hypothesis H2 "Location of large enterprise headquarters is most intensely affected by supplier-customer relationships”, cannot be eliminated.

It is worth noticing that least important factors were represented by sport and cultural facilities. These results are in discordance with currently resonating move from traditional hard location factors to their softer counterparts. Phenomenon observed within our article is explainable by less frank stance of managers answering our questionnaire: in reality they do consider also soft factors of location but these are not directly included in enterprise economy and managers intend to demonstrate their loyalty to the firm in question.

Geographically uneven spread of the capital was confirmed also via alternative approach embodied by the development of the geography of large enterprises from both quantitative and qualitative perspectives. Economic mosaic of the Czech Republic could be barely comprehended without spatially-orientated knowledge of it largest enterprises. At the same time, policy makers should intensify their interest in this kind of information.

\section{References}

Aksoy, A.; Marshall, N. 1992. The changing corporate head office and its spatial implications Regional Studies 26(2): 149-162. https://doi.org/10.1080/00343409212331346861

Ascani, A.; Crescenzi, R.; Iammarino, S. 2016. Economic institutions and the location strategies of European multinationals in their geographic neighborhood, Economic Geography 92(4): 401-429. https://doi.org/10.1080/00130095.2016.1179570

Bevan, A.; Estrin, S.; Meyer, K. 2004. Foreign investment location and institutional development in transition economies, International Business Review 13(1): 43-64. https://doi.org/10.1016/j.ibusrev.2003.05.005

Cronbach, L. J. 1960. Essentials of psychological testing. New York: Harper \& Brothers.

Dunning, J. H.; Lundan, S. M. 2008. Multinational enterprises and the global economy. Cheltenham: Edward Elgar Publishing.

Fothergill, S.; Guy, N. 1990. Retreat from the regions. Corporate change and the closure of factories. London: Jessica Kingsley Publishers.

Frobel, F.; Heinrichs, J.; Kreye, O. 1980. The new international division of labour. Cambridge: Cambridge University Press.

Hebák, P.; Hustopecky, J.; Jarosova, E.; Mala, I. 2005. Multidimensional Statistical Methods. Praha: Informatorium (in Czech).

Holland, S. 1976. Capital versus the regions. London: Macmillan. https://doi.org/10.1007/978-1-349-15773-0

Ivlev, I.; Kneppo, P.; Bartak, M. 2015. Method for selecting expert groups and determining the importance of experts' judgements for the purpose of managerial decision-making tasks in health system, E+M Ekonomie a Management 18 (2): 57-72. https://doi.org/10.15240/tul/001/2015-2-005

Johnston, R. J.; Gregory, D.; Smith, D. (Eds.) 1994. The dictionary of human geography. Oxford: Blackwell Publishers.

Lyons, D. I. 1994. Changing patterns of corporate headquarter influence 1974-89, Environment and Planning A 26(5): 733-747. https://doi.org/10.1068/a260733

Maier, G.; Tödtling, F. 1997. Regional and urban economics. Bratislava: Elita (in Slovak).

Markusen, A. R. 1985. Profit cycles, oligopoly, and regional development. Cambridge, Mass.: MIT Press.

Massey, D. 1984. Spatial divisions of labour: social structures and the geography of production. New York: Methuen. 
Massey, D. 1995. Spatial divisions of labour: social structures and the geography of production. $2^{\text {nd }}$ edition, London: Macmillan. https://doi.org/10.1007/978-1-349-24059-3

Meloun, M.; Militky, J.; Hill, M. 2012. Statistical analysis of multidimensional data in the examples. Praha: Academia (in Czech).

Mooi, E.; Sarstedt, M. 2011. A concise guide to market research. Berlin: Springer. https://doi.org/10.1007/978-3-642-12541-6

Ramsay, J. O.; Silverman, B. W. 1997. Functional data analysis. New York: Springer. https://doi.org/10.1007/978-1-4757-7107-7

Rencher, A. C.; Christensen, W. F. 2012. Methods of multivariable analysis. New Jersey: John Wiley \& Sons, Inc. https://doi.org/10.1002/9781118391686

Shephard, E.; Barnes, T. (Eds.) 2003. A companion to economic geography. Oxford: Blackwell Publishers.

Suchacek, J. 2008. Territorial development reconsidered. Ostrava: VŠB-TU.

Suchacek, J. 2015. Large enterprise branches: the Case of the Czech Republic, Economics and Sociology 8(4): 82-93. https://doi.org/10.14254/2071-789X.2015/8-4/6

Suchacek, J.; Seda, P.; Friedrich, V.; Koutsky, J. 2014. Media portrayals of regions in the Czech Republic: selected issues, E+M Ekonomie a Management 17(4): 125-140. https://doi.org/10.15240/tul/001/2014-4-010

Suchacek, J.; Seda, P.; Friedrich, V.; Koutsky, J. 2015. Regional dimension of security and accidents and their TV reflection in the Czech Republic, Transformations in Business and Economics 14(3C): 544-563.

Suchacek, J.; Seda, P.; Friedrich, V.; Wachowiak-Smolikova, R.; Wachowiak, M.P. 2016. From Regional to national clouds: TV coverage in the Czech Republic, Plos One 11(11). https://doi.org/10.1371/journal.pone.0165527

Vanhove, R.; Klaasen, L. H. 1987. Regional policy: a european approach. Avebury: Aldershot.

Van Dijk, J.; Pellenbarg, P. H. (Eds.) 1999. Demography of firms: spatial dynamics of firm behaviour. Utrecht: Nederlandse Geografische Studies.

Yserte, R. G.; Rivera, M. T. G.; Gautier, D. M. 2016. The economic crisis and the geography business network in Spain: 2000-2013, Revista de Estudios Regionales 106: 165-195.

Jan SUCHÁČEK is Associate Professor at the Faculty of Economics, VŠB - Technical University of Ostrava, the Czech Republic. His research and publications focus mainly on the urban and regional economics and development, spatial aspects of European integration and globalization. He is the author or co-author of more than 60 articles and 4 books. He has been involved in numerous domestic as well as international research projects.

Petr SEĎA is a senior lecturer at the Faculty of Economics, VŠB - Technical University of Ostrava, the Czech Republic. He has graduated from the VŠB - Technical University of Ostrava and received the MSc degree and $\mathrm{PhD}$ degree in finance engineering. His research interests are in the area of mathematical modelling in the finance and regional sciences. He is the author or co-author of more than 30 articles and 2 books.

Václav FRIEDRICH is a senior lecturer at the Faculty of Economics, VŠB - Technical University of Ostrava, the Czech Republic. His research interests involve applied statistics, marketing research and modelling as well as didactics of mathematics and statistics. He took part in numerous research projects. He is the author/co-author of many research articles and author/co-author of 2 books

Jaroslav KOUTSKÝ is Assistant Professor at the Faculty of Social and Economic Studies, Jan Evangelista Purkyne University in Usti nad Labem. His research specialization is the area of economic geography and regional economic development. Current publications and research projects are focused on the transformation process of traditionally industrialized areas and cities. 